\title{
INFLUENCE OF SELECTED PHOTOPOLYMERS ON THE RESULTING ACCURACY AND SURFACE ROUGHNESS OF THE Component in Digital Light Processing Technology
}

\author{
Jan Milde, Jozef Peterka, Frantisek Jurina, Patrik Dobrovszky, \\ Jakub Hrbal, Peter Pitek \& Jozef Martinovic
}
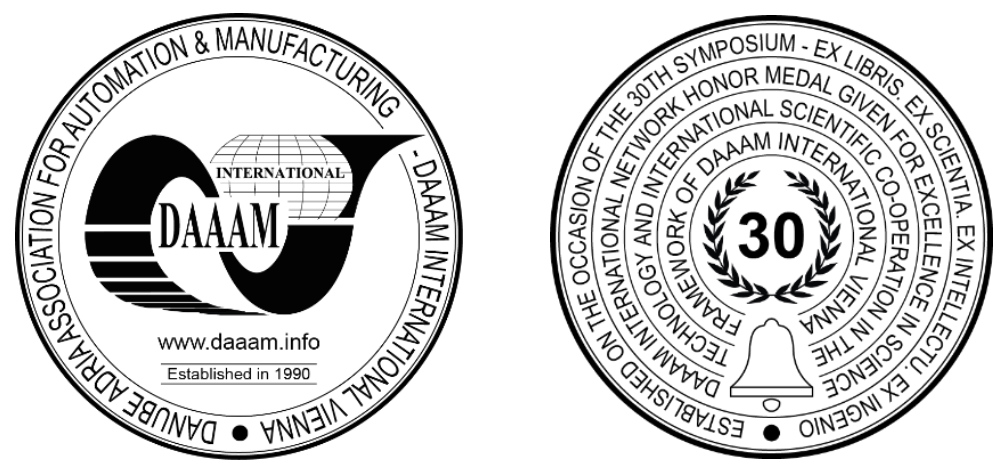

This Publication has to be referred as: Milde, J[an]; Peterka, J[ozef]; Jurina, F[rantisek]; Dobrovszky, P[atrik]; Hrbal, J[akub]; Pitek, P[eter] \& Martinovic, J[ozef] (2021). Influence of Selected Photopolymers on the Resulting Accuracy and Surface Roughness of the Component in Digital Light Processing Technology, Proceedings of the 32nd DAAAM International Symposium, pp.0235-0245, B. Katalinic (Ed.), Published by DAAAM International, ISBN 978-3-90273433-4, ISSN 1726-9679, Vienna, Austria

DOI: $10.2507 / 32$ nd.daaam.proceedings.034

\begin{abstract}
The article focuses on the influence of the used photopolymers on the dimensional accuracy and surface roughness of the component in the production process using DLP technology. Thin square parts containing four holes and four roundings were used for the experiment. According to previous research in the field of additive technologies, the authors examined the diameters of holes and surface roughness dependences. A GOM ATOS II TripleScan optical 3D scanner with a measuring volume of MV170 was used for the 3D scanning of samples. The scans were evaluated in the GOM INSPECT software. The 3D printing method was Digital Light Processing (DLP) technology and a total of five types of photopolymers from Zortrax were used. Surface roughness was investigated by portable surface roughness tester Mitutoyo SJ-210. Five samples were printed from each material used (thirty copies in total). Prints were made on a Zortrax Inkspire 3D printer. Dimensional accuracy, ie diameters of all holes and surface roughness are shown in the article in the form of graphs.
\end{abstract}

Keywords: DLP; 3D scanning; Photopolymer; Surface Roughness

\section{Introduction}

Digital light processing (DLP) is the technology of additive manufacturing allowing users to create complex parts out of photo-curable resins. DLP is highly similar to Stereolithography (SLA). When compared, both technologies use the same resins and create parts layer by layer. The main difference is that while SLA uses a laser to cure the resin, DLP uses a projector instead. Using a projector instead of the laser allows the DLP printer to illuminate the whole layer at once and by that reduces printing time. The DLP technology uses a digital micromirror device (DMD) that reflects and focuses ultraviolet (UV) light on the surfaces of photoreactive materials that polymerize in a layer-by-layer fashion. While DLP offers faster printing time, SLA on the other hand can produce parts with higher detail, since the resolution in SLA is defined by minimum laser spot size as opposed to minimum pixel size in DLP [1] [2]. 
When producing parts with additive manufacturing technologies, the produced 3D parts are sliced into 2D layers, which are then layered on top of each other. This layering can produce so called stair stepping effect. When producing parts by layering them, the stair stepping effect must always be taken into consideration, as it is main contributor to the resulting surface finish. The stair stepping effect can be generally reduced by decreasing layer thickness, however this causes the building process to be significantly slower [3]. The quality of the newly formed additive surface is affected by the layer thickness, the additive head step, the pixel size or the size of the laser beam. Here you can see an analogy with the technology of material removal - machining with machining parameters: feed rate [4], [5], [6] and tool diameter size (tip radius) [7], [8], [9]. These machining parameters also affect the accuracy of the achieved dimensions [10]. The dimensional accuracy is mainly affected by shrinking and warping of the produced part. Warpage and shrinkage in resin based additive technologies is a frequent issue, caused by incomplete polymerization of resin during the curing process [11].

Several authors already studied the surface finish and dimension accuracy of DLP produced parts. Keßler et al. studied the influence of different additive manufacturing methods, resins, and sterilizations on the accuracy of surgical implants, when compared to traditionally milled implants. Their study found out that the accuracy of printed implants was almost comparable with milled implants and that used printing devices and materials affected the precision of parts [12].

Shim et al. studied the effect of various printing orientations on printing accuracy, mechanical properties, surface characteristics, and microbial adhesion of 3D-printed resins. Their findings were that specimens printed at 90-degree orientation showed the lowest error rates for length and specimens printed at 45 degrees showed the higher surface roughness when compared with other orientations. Therefore, printing orientation should be carefully decided to fabricate products with appropriate properties [13].

Sabbah et al. studied the impact of layer thickness and storage time on the properties of dental dies produced by SLA and found out that storage time affected dimensional stability of dies, with most significant changes in the first 3 weeks of storing [14].

The author Saed produced a scaffold from the hard fabric of L-lactic acid (PLLA) synthetic resin compatible with 3D printing for digital light processing (DLP). Porous models with a pore size of 600 microns and $70 \%$ nominal porosity were designed and manufactured using the DLP technique. The effects of two process parameters, light exposure time and dye concentration, and their effect on compressive strength and morphological properties of the printed sample were investigated on these samples. The author was concluded that the synthesized polymer and the used method of $3 \mathrm{D}$ printing are suitable for fabricating scaffolds with intricate structures [15].

$3 \mathrm{D}$ printing or additive manufacturing allows the direct production of complex 3D structures according to a computeraided design [16]. DLP technology can be used in the production of prototypes, electronics [17], and biomedical devices [18]. Technology DLP is beginning to find application in the medical industry as well. Krkobabic investigated the effect of poly (ethylene glycol) 400 (PEG 400), sodium chloride ( $\mathrm{NaCl}$ ), and mannitol as hydrophilic excipients to prevent very slow and incomplete drug release from tablets made by photopolymerization using digital light processing technology (DLP). The results of this paper suggest the possibility of implementing traditional excipients in various formulations for 3D printing based on photopolymerization [19].

The quality of printed components is limited by a stair-stepping phenomenon owing to the layer-by-layer production [3], [20]. Barone researched the technology of photopolymerization of a bath based on digital light processing (DLP) to produce polymeric orthodontic appliances. A special 3D printer DLP was developed using a standard digital projector to study the effect of printing parameters on surface roughness. Dental LT Clear Resin was used to make specimens and dental appliances. Roughness measurements were performed using a Hommel Etamic T8000 measuring system, with a feed length of $1.5 \mathrm{~mm}$ and a measurement speed of $0.15 \mathrm{~mm} / \mathrm{s}$. Roughness measurements were performed on $20 \mathrm{x} 15 \mathrm{x}$ $12 \mathrm{~mm} 3$ (XYZ) printed by using two different building orientations. DLP and SLA technologies were used for experiments and sample production. The roughness of the samples produced by the developed DLP printer is very close and, in some cases, better than the roughness obtained for the samples printed by the SLA technology [21].

The Jacobs working curve is very important in obtaining highly accurate printing results in the digital light (DLP) process. The curve expresses the relationship between the absorbed UV energy and the cured thickness of the photocurable material during exposure to UV light for a particular photocurable material. The use of the Jacobson curve can significantly save time and reduce the waste of printing materials when developing new DLP printing materials. In DLP studies [22], [23] the Jacobs working curve was used to indicate the relationship between the absorbed energy of the photocurable material and the cured thickness.

Mostafa examined the roughness of the surface on the manufactured parts by P $\mu$ SLA. The author presented a physicsbased analytical model to predict the surface roughness of the parts produced by the projection micro-stereolithography additive manufacturing. The model was a function of the layer thickness and the exposure time [24].

Milde et al. investigated the influence of part orientation on the surface roughness in process of Fused Deposition Modeling (FDM). The surface roughness was measured on the simple cuboid part with the dimension $15 \times 15 \times 30 \mathrm{~mm}$. During the production of the samples, five different angles were set to the print orientation in the $\mathrm{X}$-axis. It was found that the print orientation angle has a significant effect on the surface roughness [25].

Kowsari et al. choose a more material-based approach, in their work they tried to produce an ideal formulation of photopolymers to achieve optimal resolution of final parts. Examination of in-house formulated photopolymers was performed. Results of this study showed that di(meth) acrylate-based resins should be used when production of optically clear smooth surfaces is desired, use of these resins also helped to minimize stair-stepping effect [20]. 
Mentioned authors did provide us with valuable information, which will be used in the analysis of the influence of photopolymers on surface quality and dimensional accuracy of produced parts. Results of this analysis can be considered in future research aimed at parts produced by DLP, specifically at parts produced with Zortrax branded resins. The aim of this paper is to analyze the influence of different resins on the surface roughness and dimensional accuracy of parts produced on DLP devices. Surface roughness was measured with surface roughness tester Mitutoyo SJ-210 and dimensional accuracy was analyzed with GOM ATOS II TripleScan.

\section{Statement of the problem}

The purpose of this research is to compare dimensional accuracy and surface roughness of thin parts with holes and roundings of different diameters printed from five different photopolymer materials by Zortrax Inkspire LCD / DLP 3D printer. These materials have the following designation: Basic - Grey, Bluecast - X10, PRO Black, Basic - Pigmentfree, Flexibile - Transparent Yellow. The goal of this research is to evaluate the limitations of the used photopolymers, to rule out factors that do not contribute significantly to print accuracy and to provide a practical, quantitative guide for accuracy measurement as an engineering tool. A methodology or a practical approach for calculating the accuracy and surface roughness of samples will be developed which can be used in the future to test accuracy and surface roughness. It will establish which material is more accurate and what is the reason behind it.

\section{Photopolymers}

Photopolymers are materials based on polymers / oligomers / monomers that can be selectively polymerized and / or bonded by exposure to light radiation of other wavelengths. Polymerization is very attractive today because it produces substances that can be produced by photopolymerization reactions of monomers / oligomers, which have environmental, economic and production examples. Photoinitiators absorb the irradiating light of 3D printers and initiate layer-by-layer photopolymerization reactions of monomers / oligomers [26]. Distribution of photopolymers according to the resulting properties after curing:

- Solid,

- Hard,

- Flexi,

- Castable,

- Tough,

- High strength.

\section{Curing mechanism}

The curing reaction of stereolithographic resins is an exothermic polymerization process characterized by chemical crosslinking reactions that form an infusible, insoluble, and highly crosslinked 3D network. This reaction is initiated by delivery appropriate form of energy, which depends on the stereolithographic strategy used. A general illustration of the solidification process is shown in the figure below (Fig. 1) [27]. During the curing reaction, two main events occur, independently of the stereolithographic strategy used to initiate the polymerisation process:

- Gelation - the transition from liquid to rubber,

- Vitrification - ie. transition of liquid or rubber to glass [27].

The gelation described by Gilham as a "chemical explosion" is an irreversible phenomenon and corresponds to the incipient formation of an infinite molecular network (molecular gelation), which is associated with a dramatic increase in viscosity (macroscopic gelation). At this point, the system will no longer flow and there will be two phases simultaneously: the gel phase and the salt phase. The gel phase is the gelatinized part, insoluble in non-degrading solvents, while the salt phase, which remains soluble, can be extracted with solvents. Molecular gelation is defined as the initial formation of branched molecules with infinity molecular weight and occurs at a specific fractional conversion for each system, which depends on the functionality, reactivity, and stoichiometry of the reactive substances [27], [28].

Macroscopic gel formation is associated with a significant increase in viscosity and a corresponding decrease in processability. The sudden transformation from a viscous liquid to an elastic gel or rubber corresponds to the point of the gel and defines the onset of gelatinization. As a reaction further, the amount of salt phase present in the system decreases, and the polymer becomes more and more crosslinked (Fig. 8). Molecular mobility also decreases due to limitations due to the crosslinked structure [28].

Vitrification is a gradual, thermally reversible process that corresponds to the formation of a glassy solid material due to an increase in both the crosslinking density and the molecular weight of the cured polymer. The vitrification will significantly reduce the reaction rate and the reaction will be very slow because it will be regulated by the diffusion of reactive substances. In this way, vitrification refers to the change from a reaction that is preferably kinetically controlled to a reaction that is controlled by diffusion. In this mode, the time required for reactive groups to be found is much longer [28]. 


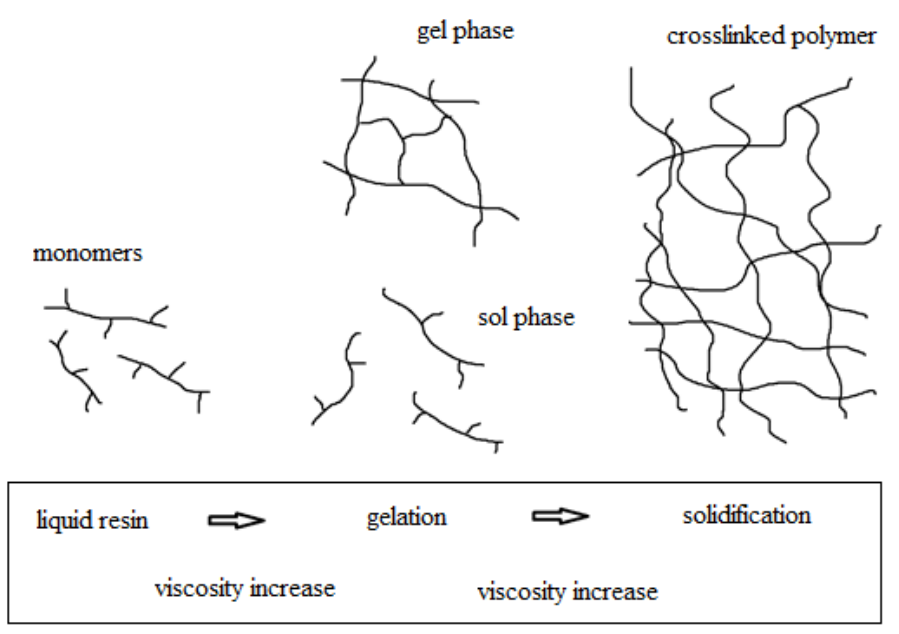

Fig. 1. Curing process

\section{Digital Light Processing (DLP)}

The main difference between SLA and DLP is in the light source used. While the SLA is a laser coordinated by galvanometers, the DLP technology is a specially designed digital light projector that cures the entire layer simultaneously. From this point of view, DLP is therefore considered to be much faster than SLA. In SLA, the laser must cure the resin using a point-to-point technique. On the other hand, the DLP projector screen flashes on the entire layer at the same time. Because DLP is a digital technology, a projected 2D image is made up of pixels. When translated into 3D, they become voxels. The DLP 3D printer's light source alone and LED screen would not work without the digital micromirror device (DMD) that is the basis of every chipset. DMD contains hundreds of thousands or even millions of small micromirrors that direct light and form a pattern of a particular layer at the bottom of the resin tank. The resolution of the printed part by DLP printing usually corresponds to the number of micromirrors inside the DMD device.

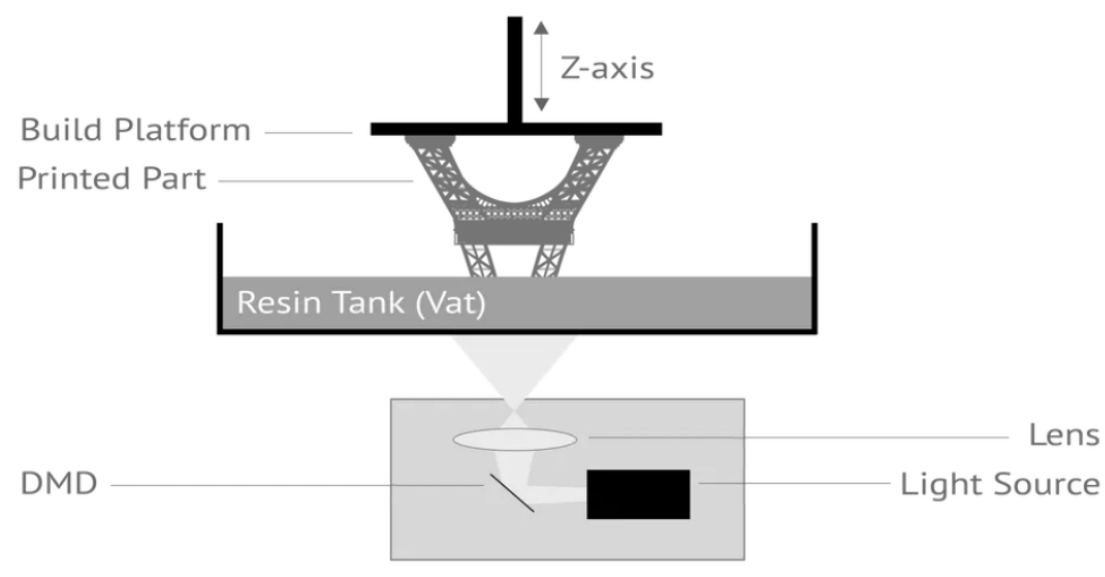

Fig. 2. Scheme of DLP technology [29]

\section{Parameters settings of DLP technology}

In this experiment was used LCD/DLP 3D printer Zortrax Inkspire. Manufacturing parameters used for all mentioned materials are shown in Tab. 1.

\begin{tabular}{|l|c|c|c|c|c|}
\hline $\begin{array}{c}\text { Manufacturing } \\
\text { parameters }\end{array}$ & Basic - Grey & Bluecast X10 & PRO Black & $\begin{array}{c}\text { Basic - } \\
\text { Pigmentfree }\end{array}$ & $\begin{array}{c}\text { Flexibile - } \\
\text { TransparentYellow }\end{array}$ \\
\hline Layer thickness [mm] & 0.05 & 0.05 & 0.05 & 0.05 & 0.05 \\
\hline Orientation in X/Y axis $\left[{ }^{\circ}\right]$ & 0 & 0 & 0 & 0 & 0 \\
\hline Infill [\%] & 100 & 100 & 100 & 100 & 100 \\
\hline Z lift distance [mm] & 5 & 5 & 5 & 5 & 5 \\
\hline Layer exposure time [s] & 10 & 10 & 10 & 10 & 10 \\
\hline
\end{tabular}

Table 1. Parameters used for manufacturing of samples 


\section{Process of digitizing}

The basis of the 3D scanning process is a scanning device, in this case, an optical 3D scanner GOM ATOS II Triple Scan and a physical component, in our case a scanned sample. 3D scanning obtains the coordinates of the scanned surface, which is referred to as a point cloud. In the next step, this point cloud is converted into a polygonal grid using special software, in other words, the points are connected into polygons (squares, triangles, or polygons). This process is called polygonization. The most used polygon format is STL.

Before scanning the sample placed uncoded reference points that are used to connect multiple waveform scanning. They also serve for better orientation of the drawn model in the software. When the reference points are in place, the sample is sprayed with anti-reflective (chalk) powder. In this way, a thin layer of coating is applied to the surface of the sample, which has the task of creating a matt or at least substantially duller surface than the scanned sample. The function of this powder is to eliminate the diffraction and refraction of incident rays, and thus to ensure a more accurate scan. The scheme of projecting the strips of structured light is shown in Fig 3.

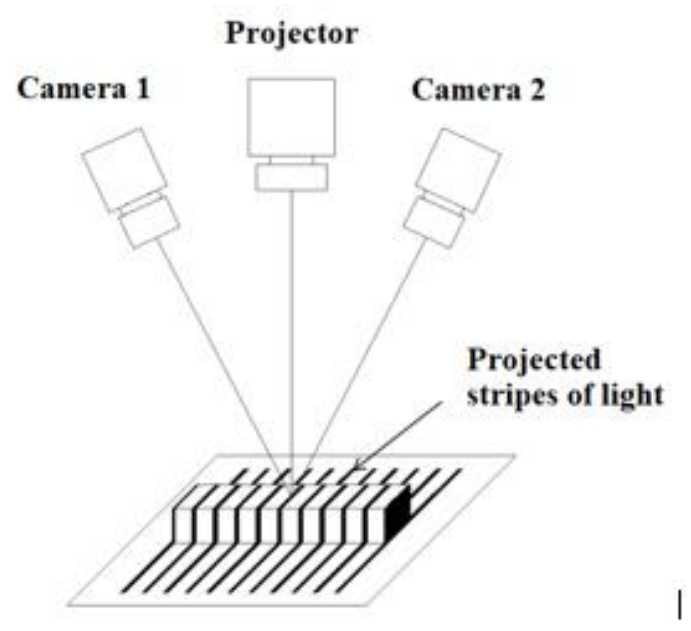

Fig. 3. Scheme of projecting stripes of structured light on the scanned object [30]

\section{Analysis of results}

Used materials in this experiment were photo-polymeric resins of Zortrax company: PRO black, basic gray, bluecast $\mathrm{X} 10$, transparent yellow, and pigment-free resins. Five specimens of each type of resin were printed (25 samples in total). When determining dimensional accuracy, flatness, and surface roughness of the component, we can measure it using inspection software for measuring. Examination of all of the examples was performed via GOM Inspect software. The analyzed sample is a thin part with holes and roundings of various diameters. These parameters were measured and evaluated for print accuracy. Otherwise, the diameter of the holes, roughness, and the overall flatness of the part was measured.

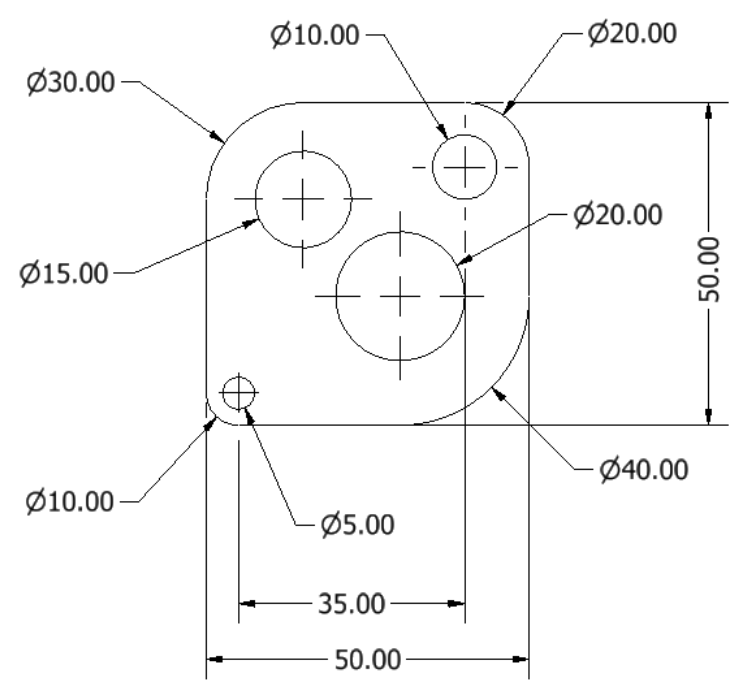

Fig. 4. Measured sample 
All measurements of internal holes showed negative values. The largest negative deviation, in this case, was for the Bluecast original material with an average value of $-0.236 \mathrm{~mm}$, while the smallest average deviation was measured for the Basic grey material with a value of $-0.059 \mathrm{~mm}$. In terms of flatness, the worst came out measured sample of Transparent yellow material, where a value of $0.760 \mathrm{~mm}$ was measured, which is almost one millimeter. This fact can be justified by the flexibility and softness of this type of material.

\begin{tabular}{|c|c|c|c|c|c|c|}
\hline $\begin{array}{c}\text { Photopolymer } \\
\text { type }\end{array}$ & sample & $\begin{array}{c}\text { hole } \varnothing 20 \\
{[\mathrm{~mm}]}\end{array}$ & $\begin{array}{c}\text { hole } \emptyset 15 \\
{[\mathrm{~mm}]}\end{array}$ & $\begin{array}{c}\text { hole } \emptyset 10 \\
{[\mathrm{~mm}]}\end{array}$ & $\begin{array}{c}\text { hole Ø5 } \\
\text { [mm] }\end{array}$ & $\begin{array}{c}\text { Flatness } \\
\text { [mm] }\end{array}$ \\
\hline \multirow{7}{*}{ Basic grey } & 1 & 19.888 & 14.865 & 9.864 & 4.918 & 1.190 \\
\hline & 2 & 19.901 & 14.887 & 9.859 & 4.948 & 1.140 \\
\hline & 3 & 19.883 & 14.954 & 9.933 & 4.958 & 1.290 \\
\hline & 4 & 19.849 & 14.885 & 9.887 & 4.926 & 1.500 \\
\hline & 5 & 19.883 & 14.881 & 9.857 & 4.956 & 0.840 \\
\hline & $\Sigma$ & 19.881 & 14.894 & 9.880 & 4.941 & 1.192 \\
\hline & $(+/-)$ & -0.119 & -0.106 & -0.120 & -0.059 & 0.192 \\
\hline \multirow{7}{*}{ PRO black } & 1 & 19.824 & 14.833 & 9.820 & 4.806 & 1.270 \\
\hline & 2 & 19.852 & 14.846 & 9.859 & 4.820 & 1.260 \\
\hline & 3 & 19.827 & 14.837 & 9.819 & 4.813 & 1.150 \\
\hline & 4 & 19.812 & 14.843 & 9.842 & 4.855 & 1.140 \\
\hline & 5 & 19.988 & 15.056 & 10.005 & 4.962 & 0.570 \\
\hline & $\Sigma$ & 19.861 & 14.883 & 9.869 & 4.851 & 1.078 \\
\hline & $(+/-)$ & -0.139 & -0.117 & -0.131 & -0.149 & 0.078 \\
\hline \multirow{7}{*}{ Bluecast X10 } & 1 & 19.744 & 14.814 & 9.857 & 4.797 & 1.360 \\
\hline & 2 & 19.727 & 14.793 & 9.809 & 4.843 & 1.330 \\
\hline & 3 & 19.817 & 14.907 & 9.898 & 4.931 & 1.340 \\
\hline & 4 & 19.765 & 14.861 & 9.850 & 4.852 & 1.470 \\
\hline & 5 & 19.765 & 14.860 & 9.848 & 4.874 & 1.450 \\
\hline & $\Sigma$ & 19.764 & 14.847 & 9.852 & 4.859 & 1.390 \\
\hline & $(+/-)$ & -0.236 & -0.153 & -0.148 & -0.141 & 0.390 \\
\hline \multirow{7}{*}{ Pigmentfree } & 1 & 19.819 & 14.815 & 9.823 & 4.800 & 1.580 \\
\hline & 2 & 19.829 & 14.849 & 9.833 & 4.881 & 1.490 \\
\hline & 3 & 19.811 & 14.818 & 9.796 & 4.872 & 1.480 \\
\hline & 4 & 19.840 & 14.874 & 9.867 & 4.917 & 1.710 \\
\hline & 5 & 19.826 & 14.804 & 9.803 & 4.875 & 1.200 \\
\hline & $\Sigma$ & 19.825 & 14.832 & 9.824 & 4.869 & 1.492 \\
\hline & $(+/-)$ & -0.175 & -0.168 & -0.176 & -0.131 & 0.492 \\
\hline \multirow{7}{*}{$\begin{array}{c}\text { Flexibile - } \\
\text { Transparent } \\
\text { yellow }\end{array}$} & 1 & 19.846 & 14.860 & 9.890 & 4.906 & 1.740 \\
\hline & 2 & 19.866 & 14.906 & 9.855 & 4.956 & 1.730 \\
\hline & 3 & 19.827 & 14.856 & 9.828 & 4.927 & 1.690 \\
\hline & 4 & 19.839 & 14.822 & 9.820 & 4.852 & 1.590 \\
\hline & 5 & 19.865 & 14.889 & 9.865 & 4.935 & 2.050 \\
\hline & $\Sigma$ & 19.849 & 14.867 & 9.852 & 4.915 & 1.760 \\
\hline & $(+/-)$ & -0.151 & -0.133 & -0.148 & -0.085 & 0.760 \\
\hline
\end{tabular}

Table 2. Evaluation of holes of samples 
From the types of materials mentioned and compared, it can be concluded that the accuracy of the printout is best achieved from a resin of a photo-polymeric material with higher hardness. Thus, in this case, the black and basic grey materials achieved the best results in terms of the accuracy of the measured deviations and properties. This phenomenon may be due to their material structure and crosslinking bonding during the curing process. It is also worth noting that harder types of materials have a better finish, and it is easier to remove excess parts or supports.

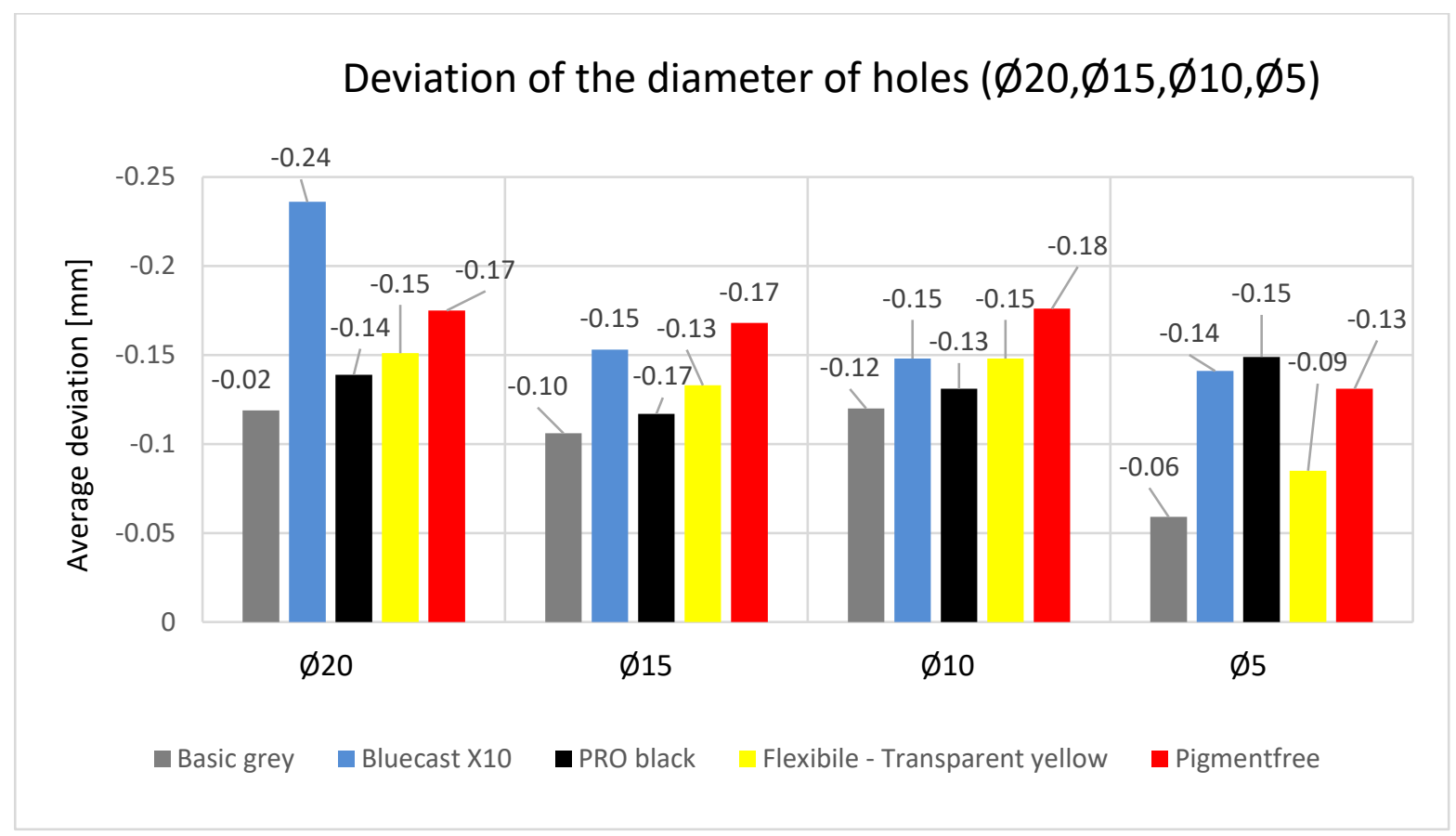

Fig. 5. Deviation of the inner diameter of holes

\section{Roughness measurement}

\section{Geometrical model of roughness}

For the theoretical calculation of the roughness of the DLP additive surface, we used analytical pixel analysis. We used the following theoretical assumptions for our analysis:

- we do not consider the inaccuracy of pixel dimensions,

- we do not consider deformation of the material during cooling,

- we do not consider the oscillations and vibrations of the 3D display in any direction (X, Y).

Our geometric model is based on the arrangement of pixels around the theoretical profile (shape). The squares represent voxels with a height $L t$ and with the dimensions of the base in the XY plane with the size of pixels of the same resolution. Gray squares represent the material after curing. White squares represent uncured material. Figure 5 shows a geometric model of the DLP profile with examples of the influence of the layer thickness $L t$ for different angles of the profile inclination $\alpha=0^{\circ}, 30^{\circ}, 45^{\circ}, 60^{\circ}, 90^{\circ}$.
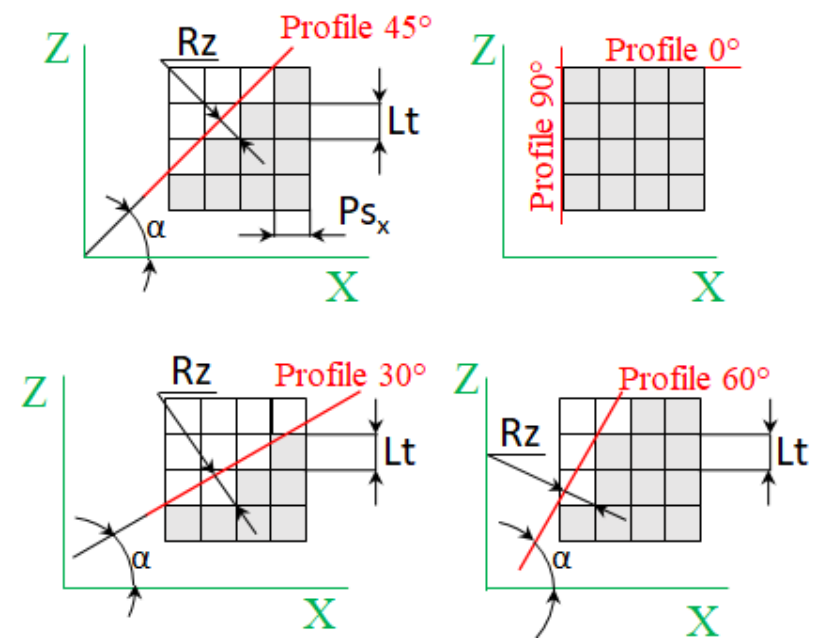

Fig. 6. Geometric model of LCD/DLP profile, influence of layer thickness for different angles of profile inclination $\alpha$. 
Where Rz is the theoretical maximum height of the irregularities of the newly formed additive DLP surface, $L t$ is layer thickness and $\mathrm{PS}_{\mathrm{x}}$ is the size of the pixel in the $\mathrm{X}$-axis direction. We can say that the surface roughness in this case is a function of the layer thickness Lt, the pixel size Psx and the angle of inclination of the profile:

$$
R_{Z}=f\left(L_{t}, P s_{x}, \alpha\right)
$$

Fig.6 shows the geometric model of the DLP profile - holes.

Resolution XY, pixel size: $\mathrm{Ps}_{\mathrm{x}}, \mathrm{Ps}_{\mathrm{y}}$

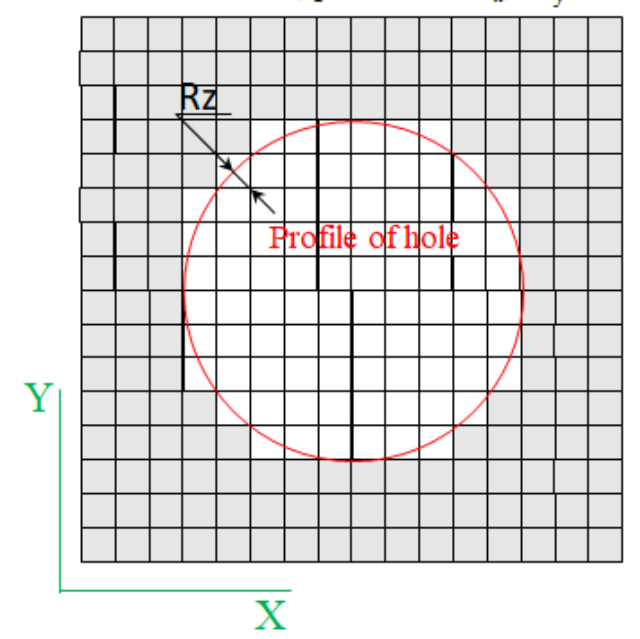

Fig. 7. Geometric model of DLP profile - hole, in XY plane

We can say that the surface roughness in this case is a function of the thickness of the pixel size $\mathrm{Ps}_{\mathrm{x}}$ and $\mathrm{Ps}_{\mathrm{y}}$, ie from the pixel density resp. resolution.

$$
R_{Z}=f\left(P s_{x}, P s_{y}\right)
$$

Overall, it can be stated that for horizontal and perpendicular surfaces, from a geometric point of view, the roughness of the additive surfaces should be better than for surfaces with a different angle of inclination.

\section{Experimental results}

In this experiment, the surface roughness of the samples was measured with a Mitutoyo SJ 210 surface tester. Surface roughness was measured on every part on the three places to eliminate bias and random errors. It was measured at a distance of $2.4 \mathrm{~mm}$. Overall, the two parameters measured roughness ( $\mathrm{Ra}$ and $\mathrm{Rz}$ ). From the data were evaluated by the average roughness values for the various parameters of roughness. Roughness was measured on the face of components made from a total of five different photopolymers. The surface roughness of all materials in the experiment showed the same dependencies except for Transparent Yellow. The arithmetical mean of surface roughness is shown in Table 3. Table 7.

\begin{tabular}{|c|c|c|c|c|c|c|}
\hline \multicolumn{9}{|c|}{ Basic grey } \\
\hline $\begin{array}{c}\text { Roughness } \\
\text { parameter }\end{array}$ & $\begin{array}{c}\text { Print 1 } \\
{[\mu \mathrm{m}]}\end{array}$ & $\begin{array}{c}\text { Print 2 } \\
{[\mu \mathrm{m}]}\end{array}$ & $\begin{array}{c}\text { Print 3 } \\
{[\mu \mathrm{m}]}\end{array}$ & $\begin{array}{c}\text { Print 4 } \\
{[\mu \mathrm{m}]}\end{array}$ & $\begin{array}{c}\text { Print 5 } \\
{[\mu \mathrm{m}]}\end{array}$ & $\begin{array}{c}\text { Arithmetical } \\
\text { mean } \\
{[\mu \mathrm{m}]}\end{array}$ \\
\hline $\mathrm{Ra}$ & 0.233 & 0.184 & 0.232 & 0.943 & 0.881 & $\mathbf{0 . 4 9 4}$ \\
\hline $\mathrm{Rz}$ & 1.700 & 0.976 & 1.626 & 5.233 & 5.103 & $\mathbf{2 . 9 2 7}$ \\
\hline
\end{tabular}

Table 3. Ra and Rz values for material Basic grey

\begin{tabular}{|c|c|c|c|c|c|c|}
\hline \multicolumn{9}{|c|}{ Bluecast X10 } \\
\hline $\begin{array}{c}\text { Roughness } \\
\text { parameter }\end{array}$ & $\begin{array}{c}\text { Print 1 } \\
{[\mu \mathrm{m}]}\end{array}$ & $\begin{array}{c}\text { Print 2 } \\
{[\mu \mathrm{m}]}\end{array}$ & $\begin{array}{c}\text { Print 3 } \\
{[\mu \mathrm{m}]}\end{array}$ & $\begin{array}{c}\text { Print 4 } \\
{[\mu \mathrm{m}]}\end{array}$ & $\begin{array}{c}\text { Print 5 } \\
{[\mu \mathrm{m}]}\end{array}$ & $\begin{array}{c}\text { Arithmetical } \\
\text { mean } \\
{[\mu \mathrm{m}]}\end{array}$ \\
\hline $\mathrm{Ra}$ & 0.787 & 0.282 & 0.334 & 0.287 & 0.554 & $\mathbf{0 . 4 4 9}$ \\
\hline $\mathrm{Rz}$ & 4.781 & 1.388 & 1.886 & 1.531 & 2.551 & $\mathbf{2 . 4 2 7}$ \\
\hline
\end{tabular}

Table 4. Ra and Rz values for material Bluecast X10 


\begin{tabular}{|c|c|c|c|c|c|c|}
\hline \multicolumn{7}{|c|}{ PRO Black } \\
\hline $\begin{array}{c}\text { Roughness } \\
\text { parameter }\end{array}$ & $\begin{array}{c}\text { Print 1 } \\
{[\mu \mathrm{m}]}\end{array}$ & $\begin{array}{c}\text { Print 2 } \\
{[\mu \mathrm{m}]}\end{array}$ & $\begin{array}{c}\text { Print 3 } \\
{[\mu \mathrm{m}]}\end{array}$ & $\begin{array}{c}\text { Print 4 } \\
{[\mu \mathrm{m}]}\end{array}$ & $\begin{array}{c}\text { Print 5 } \\
{[\mu \mathrm{m}]}\end{array}$ & $\begin{array}{c}\text { Arithmetical } \\
\text { mean } \\
{[\mu \mathrm{m}]}\end{array}$ \\
\hline $\mathrm{Ra}$ & 0.374 & 0.182 & 0.515 & 0.154 & 0.824 & $\mathbf{0 . 4 1 0}$ \\
\hline $\mathrm{Rz}$ & 2.465 & 1.099 & 3.055 & 0.927 & 4.306 & $\mathbf{2 . 3 7 0}$ \\
\hline
\end{tabular}

Table 5. Ra and Rz values for material PRO Black

\begin{tabular}{|c|c|c|c|c|c|c|}
\hline \multicolumn{7}{|c|}{ Transparent Yellow } \\
\hline $\begin{array}{c}\text { Roughness } \\
\text { parameter }\end{array}$ & $\begin{array}{c}\text { Print 1 } \\
{[\mu \mathrm{m}]}\end{array}$ & $\begin{array}{c}\text { Print 2 } \\
{[\mu \mathrm{m}]}\end{array}$ & $\begin{array}{c}\text { Print 3 } \\
{[\mu \mathrm{m}]}\end{array}$ & $\begin{array}{c}\text { Print 4 } \\
{[\mu \mathrm{m}]}\end{array}$ & $\begin{array}{c}\text { Print 5 } \\
{[\mu \mathrm{m}]}\end{array}$ & $\begin{array}{c}\text { Arithmetical } \\
\text { mean } \\
{[\mu \mathrm{m}]}\end{array}$ \\
\hline $\mathrm{Ra}$ & 1.123 & 0.865 & 1.076 & 1.118 & 0.951 & $\mathbf{1 . 0 2 7}$ \\
\hline $\mathrm{Rz}$ & 6.593 & 4.834 & 6.201 & 6.413 & 5.182 & $\mathbf{5 . 8 4 4}$ \\
\hline
\end{tabular}

Table 6. Ra and Rz values for material Transparent Yellow

\begin{tabular}{|c|c|c|c|c|c|c|}
\hline \multicolumn{7}{|c|}{ Pigment-free } \\
\hline $\begin{array}{l}\text { Roughness } \\
\text { parameter }\end{array}$ & $\begin{array}{c}\text { Print } 1 \\
{[\mu \mathrm{m}]}\end{array}$ & $\begin{array}{c}\text { Print } 2 \\
{[\mu \mathrm{m}]}\end{array}$ & $\begin{array}{c}\text { Print } 3 \\
{[\mu \mathrm{m}]}\end{array}$ & $\begin{array}{c}\text { Print } 4 \\
{[\mu \mathrm{m}]}\end{array}$ & $\begin{array}{c}\text { Print } 5 \\
{[\mu \mathrm{m}]}\end{array}$ & $\begin{array}{c}\text { Arithmetical } \\
\text { mean } \\
{[\mu \mathrm{m}]}\end{array}$ \\
\hline $\mathrm{Ra}$ & 1.131 & 0.236 & 0.820 & 0.230 & 0,194 & 0.522 \\
\hline $\mathrm{Rz}$ & 6.413 & 1.161 & 5.306 & 1.474 & 1.360 & 3.143 \\
\hline
\end{tabular}

Table 7. Ra and Rz values for material Pigment-free

\section{Surface roughness vs used photopolymer}

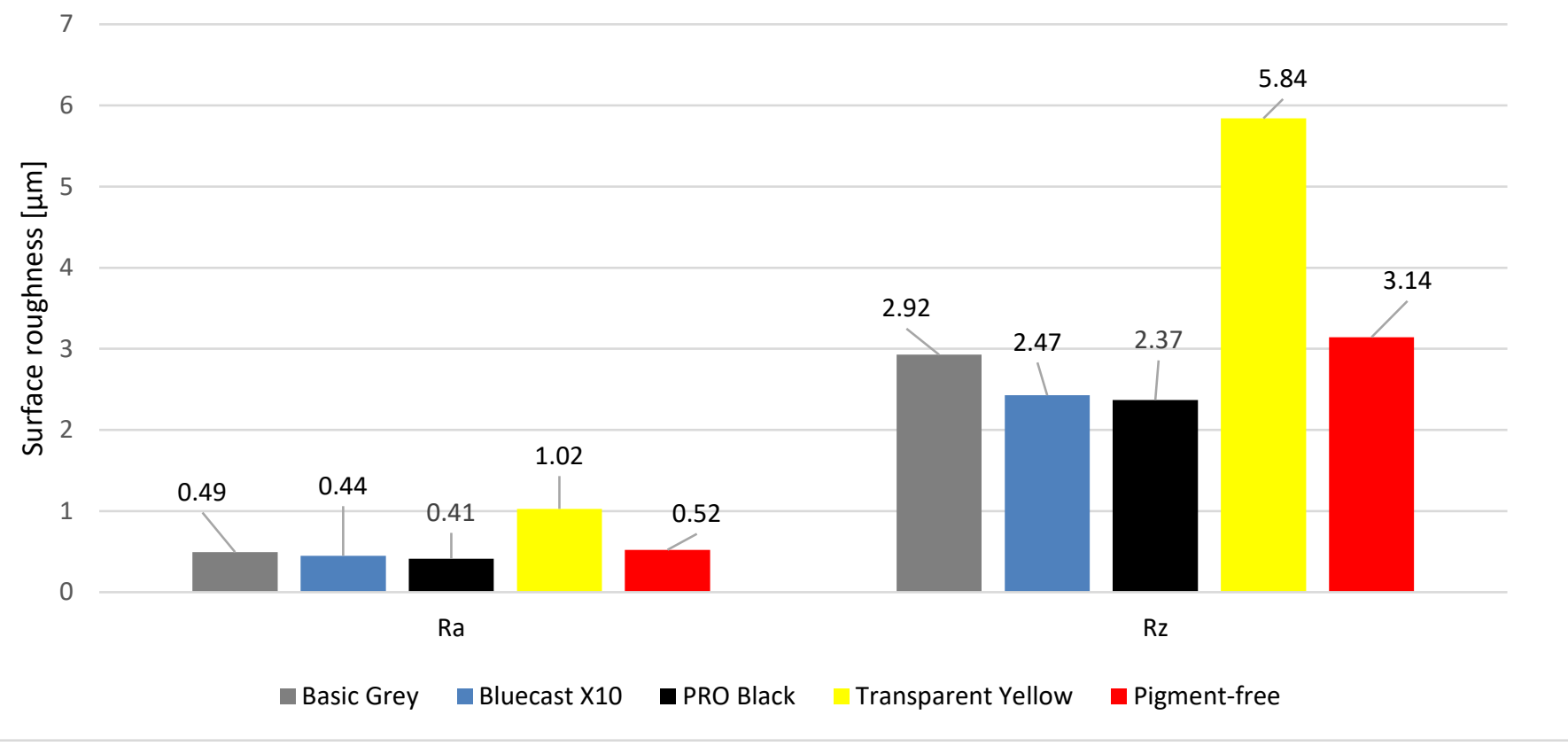

Fig. 8. Ra and Rz vs used photopolymer

\section{Conclusion}

These measured facts result from a slight bending due to shrinkage of the plastic material. Harder materials (Black, Basic grey) showed better properties in overall flatness. These materials have better bonding during the solidification process. Therefore, they can reach a better finish with a greater grade of accuracy. Materials with the harder structures are evaluated as better in terms of scratch resistance or overall resistance to surface damage. Softer materials as Transparent yellow or Pigmentfree showed similar deviation to harder materials in terms of accuracy of the holes. 
On the other hand, these materials are flexible and softer, therefore their crosslinking process is with long chain segments, which makes these materials reminiscent of hard rubber structure. All in all, compared materials do not have an extreme difference in deviation except for flatness.

As can be seen in Fig 5, surface roughness values are similar in 4 out of 5 resins. In the case of Transparent Yellow resin, the measured values of surface roughness when compared with other resins are roughly twice as high. This fact can be contributed to the unique optical property of resin, since it is the only one of tried resins that were transparent. Therefore, projected UV light from DLP device while curing next layer in order might have reached already cured layers, resulting in overcuring, respectively partially increased layer exposure time in comparison to non-transparent resins. This applies to the possible process of post-processing in IPA and UV chambers as well. However, more research will be needed to address and properly analyze this outcome. It must also be noted, that while mean values of roughness are similar, the deviation in roughness values of individual prints is observable. Although the individual surface roughness values of Ra are erratic, they generally do not reach values higher than $1 \mu \mathrm{m}$, in most cases not reaching $0.5 \mu \mathrm{m}$.

\section{Acknowledgments}

The article was written with the support of the project VEGA 1/0019/20.

\section{References}

[1] J. Borrello, P. Nasser, J. C. Iatridis, and K. D. Costa, (2018). "3D printing a mechanically-tunable acrylate resin on a commercial DLP-SLA printer,” Addit. Manuf., vol. 23, pp. 374-380, Oct., doi: 10.1016/j.addma.2018.08.019.

[2] J. Schmidt, H. Elsayed, E. Bernardo, and P. Colombo, (2018). "Digital light processing of wollastonite-diopside glass-ceramic complex structures," J. Eur. Ceram. Soc., vol. 38, no. 13, pp. 4580-4584, , doi: 10.1016/j.jeurceramsoc.2018.06.004.

[3] Y. Pan, X. Zhao, C. Zhou, and Y. Chen, (2012). "Smooth surface fabrication in mask projection based stereolithography," in Journal of Manufacturing Processes, vol. 14, no. 4, pp. 460-470, doi: 10.1016/j.jmapro.2012.09.003.

[4] M. Beno, M. Zvoncan, M. Kovac, et al., (2013). "Circular interpolation and positioning accuracy deviation measurement on five axis machine tools with different structures". Tehnicki vjesnik-technical gazette, Volume: 2 , Issue: 3, Pages: 479-484,

[5] T. Vopat, J. Peterka, V. Simna et al., (2014). "The Influence of Different Types of Copy Milling on the Surface Roughness and Tool Life of End Mills". Conference: 25th DAAAM International Symposium on Intelligent Manufacturing and Automation Location: oldest technical univ, Vienna, AUSTRIA Date: NOV 26-29, Sponsor(s): Vienna Univ Technology, 25TH DAAAM International Symposium On Intelligent Manufacturing And Automation, 2014, Book Series: Procedia Engineering, Volume: 10, Pages: 868-876

[6] J. Peterka. (2004). "A new approach to calculating the arithmetical mean deviation of a profile during copy milling". Strojniski vestnik - journal of mechanical engineering. Volume: 50, Issue: 12, Pages: 594-597

[7] M. Polakovic, I. Buransky, j. Peterka, (2008). "Simulation concept for machined surface roughness and shape deviation prediction". Conf. 19th Intern. Sympos. of DAAAM, Trnava, Slovakia, Oct 22-25, Annals of DAAAM Proceedings of the 19th Int. DAAAM Symp. Book Series: Annals of DAAAM and Proceedings, pages: 1089-1090

[8] J. Peterka, P. Pokorny, (2013). " Influence of the Lead Angle from the Vertical Axis Milling on Effective Radius of the Cutter " Conference: 7th International Congress of Precision Machining Location: Miskolc, HUNGARY Date: OCT 03-05, 2013 Sponsor(s): Int Visegrad Fund; SANDVIK Cromant. Precision Machining VII, Book Series: Key Engineering Materials, Volume: 581, Pages: 44-49

[9] K. Sentyakov, J. Peterka, V. Smirnov et al. (2020). "Modeling of Boring Mandrel Working Process with Vibration Damper" Materials, Volume: 13, Issue: 8, rticle Number: 1931

[10] J. Peterka, P. Pokorny, S. Vaclav. (2008). "CAM strategies and surfaces accuracy“. Conference: 19th International Symposium of the Danube-Adria-Association-for-Automation-and-Manufacturing Location: Trnava, SLOVAKIA Date: OCT 22-25, ANNALS OF DAAAM FOR 2008 \& Proceedings Of The 19th International Daaam Symposium, Book Series: Annals of DAAAM and Proceedings, Pages: 1061-1062, Published: 2008

[11] N. Nestler, C. Wesemann, B. C. Spies, F. Beuer, and A. Bumann, (2021). "Dimensional accuracy of extrusion- and photopolymerization-based 3D printers: In vitro study comparing printed casts,” J. Prosthet. Dent., vol. 125, no. 1, pp. 103-110, doi: 10.1016/j.prosdent.2019.11.011.

[12] A. Keßler, M. Dosch, M. Reymus, and M. Folwaczny, (2021). "Influence of 3D- printing method, resin material, and sterilization on the accuracy of virtually designed surgical implant guides," J. Prosthet. Dent., , doi: 10.1016/j.prosdent.2020.08.038.

[13] J. S. Shim, J. E. Kim, S. H. Jeong, Y. J. Choi, and J. J. Ryu,(2020). "Printing accuracy, mechanical properties, surface characteristics, and microbial adhesion of 3D-printed resins with various printing orientations," J. Prosthet. Dent., vol. 124, no. 4, pp. 468-475, doi: 10.1016/j.prosdent.2019.05.034.

[14] A. Sabbah, G. Romanos, and R. Delgado-Ruiz, (2012). "Impact of layer thickness and storage time on the properties of 3D-printed dental dies,” Materials (Basel)., vol. 14, no. 3, pp. 1-10, doi: 10.3390/ma14030509. 
[15] A. Bagheri Saed, A. H. Behravesh, S. Hasannia, S. A. Alavinasab Ardebili, B. Akhoundi, and M. Pourghayoumi, (2019). "Functionalized poly L-lactic acid synthesis and optimization of process parameters for 3D printing of porous scaffolds via digital light processing (DLP) method,” J. Manuf. Process., vol. 56, no., pp. 550-561, 2020, doi: 10.1016/j.jmapro.2020.04.076.

[16] I. Buransky, L. Morovic, J. Peterka, (2013). "Application of Reverse Engineering for Redesigning and Manufacturing of a Printer Spare Part". Conference: 4th International Conference on Manufacturing Science and Engineering (ICMSE 2013) Location: Dalian, People R China, Date: MAR 30-31, 2013, Sponsor(s): NE Univ; Harbin Inst Technol; Jilin Univ., Material Design, Processing And Applications, Parts 1-4, Book Series: Advanced Materials Research, Volume: 690-693, Pages: 2708-2712,

[17] Q. Mu et al., (2017). "Digital light processing 3D printing of conductive complex structures," Addit. Manuf., vol. 18, pp. 74-83, doi: 10.1016/j.addma.2017.08.011.

[18] F. Chen et al., "Preparation and biological evaluation of ZrO2 all-ceramic teeth by DLP technology, (2020). " Ceram. Int., vol. 46, no. 8, pp. 11268-11274, doi: 10.1016/j.ceramint.2020.01.152.

[19] M. Krkobabić, D. Medarević, S. Cvijić, B. Grujić, and S. Ibrić, (2019). "Hydrophilic excipients in digital light processing (DLP) printing of sustained release tablets: Impact on internal structure and drug dissolution rate," Int. J. Pharm., vol. 572, no. July, p. 118790, doi: 10.1016/j.ijpharm.2019.118790.

[20] K. Kowsari et al., (2018). "Photopolymer formulation to minimize feature size, surface roughness, and stair-stepping in digital light processing-based three-dimensional printing," Addit. Manuf., vol. 24, pp. 627-638, doi: 10.1016/j.addma.2018.10.037.

[21] S. Barone, P. Neri, A. Paoli, A. V. Razionale, and F. Tamburrino, (2019). "Development of a DLP 3D printer for orthodontic applications,” Procedia Manuf., vol. 38, no. 2019, pp. 1017-1025, doi: 10.1016/j.promfg.2020.01.187.

[22] Y. Li, Q. Mao, J. Yin, Y. Wang, J. Fu, and Y. Huang, (2021). "Theoretical prediction and experimental validation of the digital light processing (DLP) working curve for photocurable materials," Addit. Manuf., vol. 37, no. August 2020, p. 101716, doi: 10.1016/j.addma.2020.101716.

[23] C. Hofstetter, S. Orman, S. Baudis, and J. Stampfl, (2018). "Combining cure depth and cure degree, a new way to fully characterize novel photopolymers," Addit. Manuf., vol. 24, no. September, pp. 166-172, doi: 10.1016/j.addma.2018.09.025.

[24] P. Cirp et al., (2020). "Investigation of Light-Induced of Surface Roughness in Projection Micro- Stereolithography Additive Manufacturing ( P $\mu$ SLA ) Stereolithography Additive Manufacturing A new method," Procedia CIRP, vol. 92, no. ii, pp. 187-193, doi: 10.1016/j.procir.2020.05.177.

[25] J. Milde, F. Jurina, J. Peterka, P. Dobrovszký, J. Hrbál and J. Martinovič, (2021). “Influence of part orientation on the surface roughness in the process of Fused Deposition Modeling." ICIEM 2021 RUDN University, moscow, Russia, April 28-30, 2021, in the press.

[26] Materialpro3d, (2019). materialpro3d. [Online] Available at: https://www.materialpro3d.sk/slovnikmaterialov/fotopolymery

[27] Bártolo, P. J., (2011). Stereolitography: Materials, processes and applications. s.l.:s.n.

[28] Gillham, J. K., (1979). Award address information and properties of network polymeric materials. s.1.:s.n.

[29] Gregurić, L., (2018). all3dp. [Online] Available at: https://all3dp.com/2/what-is-a-dlp-3d-printer-3d-printingsimply-explained/

[30] I. Buransky, (2020). Ateliér počítačovej podpory III, Trnava: s.n 